\title{
MODELING DRIVER DISTANCE RECOGNITION AND SPEED PERCEPTION AT NIGHT FOR FREEWAY SPEED LIMIT SELECTION IN CHINA
}

\author{
G. Z. $\mathrm{CHENG}^{1}$, X. D. $\mathrm{SUN}^{2}$ \& J. HAN ${ }^{1}$ \\ ${ }^{1}$ School of Transportation Science and Engineering, Harbin Institute of Technology, China. \\ ${ }^{2}$ Department of Civil Engineering, University of Louisiana at Lafayette, USA.
}

\begin{abstract}
Developing a proper speed limit for freeway is critical for roadway safety. Due to the difference in visibility between day and night, it is necessary to have different speed limits for the two time periods on freeways with changing geometric features. Aiming to reduce the number of crashes caused by speeding at night on freeways, an exploratory study was conducted on the maximum speed limit at night. In order to investigate the potential relationship between drivers' distance recognition and driving speed and between speed perception and driving speed under different geometric design features, an experiment was carried out on a 22-km-long freeway segment on Chang-song freeway in China. Based on round-trips made by 10 drivers during day and night on this segment, drivers' recognition distance (distance between a sign and the location where the sign was clearly recognized the first time) and estimated speed were recorded. The data analysis results show that driver recognition distance at night decreases by about $7 \%$ compared with recognition distance at daytime. The accuracy of driver speed perception at nighttime is only $29 \%$, whereas it is $67 \%$ at daytime. With the collected data, several multivariate non-linear regression models were established to capture the relationship among the variables of recognition distance, estimated speed at night, driving speed, and highway alignment indexes. Then the modeling results were used to develop the speed limit model by physical equations. A case study is introduced at the end of the paper.
\end{abstract}

Keywords: Freeway, traffic safety, nighttime, recognition distance, estimated speed, maximum speed limit.

\section{INTRODUCTION}

Being a relatively new type of highway to most drivers in China, crashes on Chinese freeways are closely related to high speed. Setting proper speed limit at night has been realized as a potential crash countermeasure for freeways in China. The different visibility between day and night necessitates for different speed limits on freeways. Understanding the impact of night visibility on driver's visual recognition ability and speed estimation has been an interesting study subject for many years. Related references are listed in Table 1.

In summary, in an earlier study on driver's distance recognition, the impacts of lighting and speed were considered. However, as an important influence factor, highway alignment was neglected. On the other hand, in another study on driver's estimated speed, only its deviation was analyzed statistically or the influence factors of deviation were analyzed qualitatively, but the changing rule of driver's speed perception was not given quantitatively and corresponding models were not established. Considering the difference in driving behavior among different countries, particularly between developed countries and developing countries, it is important to investigate how drivers' performance is affected by freeway design elements and driving speed to develop a proper nighttime speed limit. The purpose of the project was to study how to properly develop freeway maximum speed limit at night based on driver's distance recognition and speed perception under different highway design features and driving speeds. The paper can give a contribution to existing knowledge, but the results are still those of an exploratory study. 
Table 1: Related references.

\begin{tabular}{|c|c|c|}
\hline No. & Authors and year & Features of the research \\
\hline 1 & $\begin{array}{l}\text { Konstantopoulos et al., } \\
2010[1]\end{array}$ & $\begin{array}{l}\text { Low visibility decreased the validity of driver's visual } \\
\text { search at night. }\end{array}$ \\
\hline 2 & Easa et al., 2010 [2] & $\begin{array}{l}\text { Improved lighting was helpful for boosting driver's visual } \\
\text { recognition ability to traffic sign on straight section. }\end{array}$ \\
\hline 3 & $\begin{array}{l}\text { Babizhayev et al., } \\
2009 \text { [3] }\end{array}$ & $\begin{array}{l}\text { Glare affected driving characteristics greatly with the } \\
\text { increasing age of drivers. }\end{array}$ \\
\hline 4 & $\begin{array}{l}\text { Hua \& Donnell, } \\
2010[4]\end{array}$ & $\begin{array}{l}\text { Establishing driver's acceleration and deceleration models } \\
\text { on rural highway at night. }\end{array}$ \\
\hline 5 & $\begin{array}{l}\text { Horberry et al., } \\
2006[5]\end{array}$ & $\begin{array}{l}\text { Enhanced traffic sign was advantageous to drivers } \\
\text { at night. }\end{array}$ \\
\hline 6 & Baker, 1999 [6] & $\begin{array}{l}\text { Drivers tend to underestimate their driving speed under } \\
\text { limited light conditions at night. }\end{array}$ \\
\hline 7 & $\begin{array}{l}\text { Campbell et al., } \\
2010 \text { [7] }\end{array}$ & $\begin{array}{l}\text { If drivers underestimate or overestimate their travel speed, } \\
\text { they will travel faster or slower than they expect. }\end{array}$ \\
\hline 8 & Suh et al., 2006 [8] & $\begin{array}{l}\text { Limited lighting condition at night made drivers feel that } \\
\text { they were driving slowly, because of which they would } \\
\text { accelerate, resulting in speeding. }\end{array}$ \\
\hline 9 & $\begin{array}{l}\text { Henriette et al., } \\
2009 \text { [9] }\end{array}$ & $\begin{array}{l}\text { Drivers' speed perception in countries with a low accident } \\
\text { rate was more accurate than that in countries with a high } \\
\text { accident rate. }\end{array}$ \\
\hline 10 & $\begin{array}{l}\text { Pasetto \& Manganaro, } \\
2009 \text { [10] }\end{array}$ & $\begin{array}{l}\text { Drivers decreased speed stably at daytime, but driver's } \\
\text { speed perception was not stable at night. }\end{array}$ \\
\hline 11 & Mannering, 2009 [11] & $\begin{array}{l}\text { Drivers' perception to speeding was affected by their age, } \\
\text { sex, and nationality greatly. }\end{array}$ \\
\hline
\end{tabular}

\section{EXPERIMENTS DESIGN}

A segment on Chang-Song freeway with a design speed of $100 \mathrm{~km} / \mathrm{h}$ connecting the cities of Chang-Chun and Song-Yuan was selected for the experiment. This 22-km-long freeway segment was divided into 18 sections based on the geometric design features, particularly, the horizontal curves and slopes. Table 2 lists the classification of experimental section.

Ten non-professional drivers with 3-10 years of driving experience participated in this experiment. Each driver was required to abstain from drugs and alcohol during the experiment. Smoking and cell phone were not allowed. The experiment time was set at 9:00 to 11:00 for daytime and 21:00 to 23:00 for nighttime. Each driver drove six round-trips on this segment at both daytime and nighttime in the same car with six different speeds, i.e. $70 \mathrm{~km} / \mathrm{h}, 80 \mathrm{~km} / \mathrm{h}$, $90 \mathrm{~km} / \mathrm{h}, 100 \mathrm{~km} / \mathrm{h}, 110 \mathrm{~km} / \mathrm{h}$, and $120 \mathrm{~km} / \mathrm{h}$. There are 42 traffic signs along this segment.

Once the vehicle reached the desired speed $v$, the designated on-board passage would record the time when the driver recognized a sign ahead as $t_{1}$ and again record the time $t_{2}$ as the vehicle passing by the sign. A stopwatch was used to record the timing. At the same time, drivers were requested not to see the speedometer and to report his estimated speed value, which was also recorded. Thus, each driver's recognition distance $S$ was calculated as below:

$$
S=v \times\left(t_{2}-t_{1}\right)
$$


Table 2: Classification of experimental section.

\begin{tabular}{|c|c|c|c|c|}
\hline \multirow{2}{*}{$\begin{array}{l}\text { Longitudinal } \\
\text { Slope } i(\%)\end{array}$} & \multicolumn{4}{|c|}{ Horizontal curve radius $R(\mathrm{~m})$} \\
\hline & $0 \leq R \leq 700$ & $700<R \leq 4000$ & $4000<R \leq 10000$ & $R>10000$ \\
\hline $0 \leq i \leq 2$ & $\begin{array}{l}\text { Curve with } \\
\text { little radius }\end{array}$ & $\begin{array}{l}\text { Curve with } \\
\text { medium radius }\end{array}$ & $\begin{array}{l}\text { Curve with } \\
\text { large radius }\end{array}$ & $\begin{array}{l}\text { Flat and straight } \\
\text { section }\end{array}$ \\
\hline $2<i \leq 4$ & $\begin{array}{l}\text { Curve slope } \\
\text { with a small } \\
\text { radius }\end{array}$ & $\begin{array}{l}\text { Curve slope } \\
\text { with a medium } \\
\text { radius }\end{array}$ & $\begin{array}{l}\text { Curve slope } \\
\text { with a large } \\
\text { radius }\end{array}$ & $\begin{array}{l}\text { Straight and } \\
\text { slope section }\end{array}$ \\
\hline
\end{tabular}

Table 3: Average recognition distance at daytime and nighttime.

\begin{tabular}{|c|c|c|c|c|c|c|c|c|c|c|c|c|}
\hline \multirow{2}{*}{$\begin{array}{l}\text { Driving speed } \\
(\mathrm{km} / \mathrm{h}) \\
\text { Recognition } \\
\text { distance }(\mathrm{m})\end{array}$} & \multicolumn{6}{|c|}{ At daytime } & \multicolumn{6}{|c|}{ At night } \\
\hline & 70 & 80 & 90 & 100 & 110 & 120 & 70 & 80 & 90 & 100 & 110 & 120 \\
\hline Curve with little radius & 378 & 341 & 321 & 305 & 299 & 295 & 291 & 282 & 280 & 269 & 263 & 258 \\
\hline $\begin{array}{l}\text { Curve slope with } \\
\text { medium radius }\end{array}$ & 361 & 334 & 318 & 313 & 279 & 289 & 313 & 302 & 291 & 276 & 269 & 270 \\
\hline $\begin{array}{l}\text { Curve with medium } \\
\text { radius }\end{array}$ & 470 & 427 & 372 & 359 & 331 & 324 & 327 & 321 & 318 & 279 & 261 & 261 \\
\hline $\begin{array}{l}\text { Curve slope with large } \\
\text { radius }\end{array}$ & 403 & 382 & 359 & 330 & 321 & 312 & 361 & 358 & 338 & 305 & 301 & 286 \\
\hline Curve with large radius & 496 & 432 & 415 & 371 & 330 & 327 & 358 & 349 & 331 & 313 & 286 & 284 \\
\hline $\begin{array}{l}\text { Straight and slope } \\
\text { section }\end{array}$ & 417 & 391 & 356 & 327 & 313 & 303 & 446 & 433 & 418 & 366 & 331 & 303 \\
\hline Flat and straight section & 455 & 423 & 409 & 350 & 345 & 323 & 462 & 450 & 423 & 373 & 356 & 319 \\
\hline
\end{tabular}

\section{DRIVER DISTANCE RECOGNITION}

\subsection{Between daytime and nighttime}

Total number of data samples is 2520 , including 240 data sets on curve with small radius, 120 data sets on curve slope with medium radius, 840 data sets on curve with medium radius, 120 data sets on curve slope with large radius, 600 data sets on curve with large radius, 120 data sets on straight and slope section, and 480 data sets on flat and straight sections. However, curve slope with small radius has no observations. The average recognition distances at different driving speed and alignment during daytime and nighttime are summarized in Table 3.

As shown in Table 2, driver recognition distance at night decreases by about $7 \%$ compared with recognition distance at daytime. Driver's recognition distance increases with the decrease of driving speed at both daytime and nighttime. There is also a clear pattern of driving recognition distance versus the alignment type. 


\subsection{Recognition distance at night}

Driver's recognition distance at night varies with driving speed, horizontal curve radius, and longitudinal slope. The distribution of recognition distance versus driving speed at night is illustrated in Fig. 1. As shown in Fig. 1, as driving speed increases, recognition distance decreases.

The distribution of recognition distance versus horizontal curve radius at night is illustrated in Fig. 2. From Fig. 2, it is clear that, with the increase of horizontal curve radius, recognition distance at night also increases, so does the standard error.

The distribution of recognition distance versus longitudinal slope at night is illustrated in Fig. 3. As expected, using the car's headlight recognition distance is at a maximum when

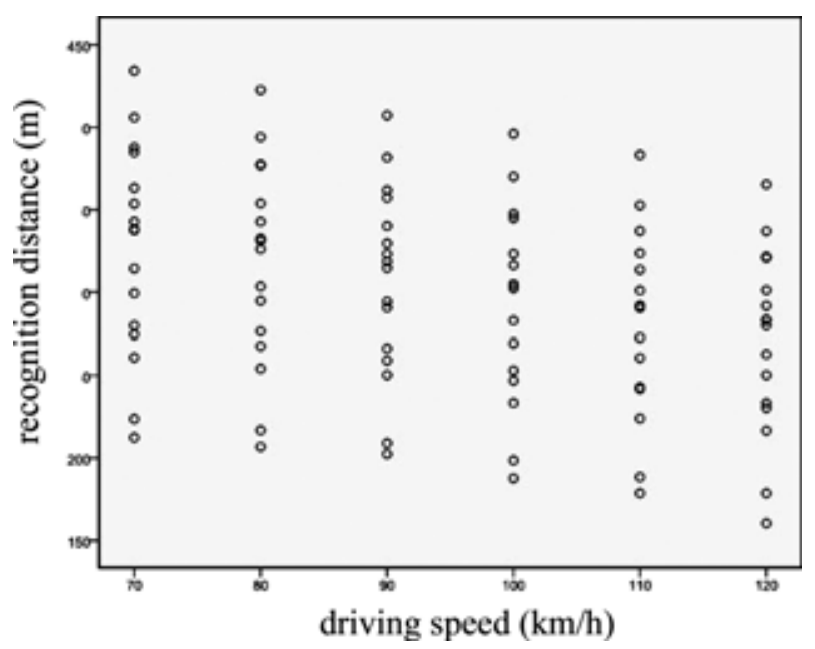

Figure 1: Distribution of recognition distance versus driving speed at night.

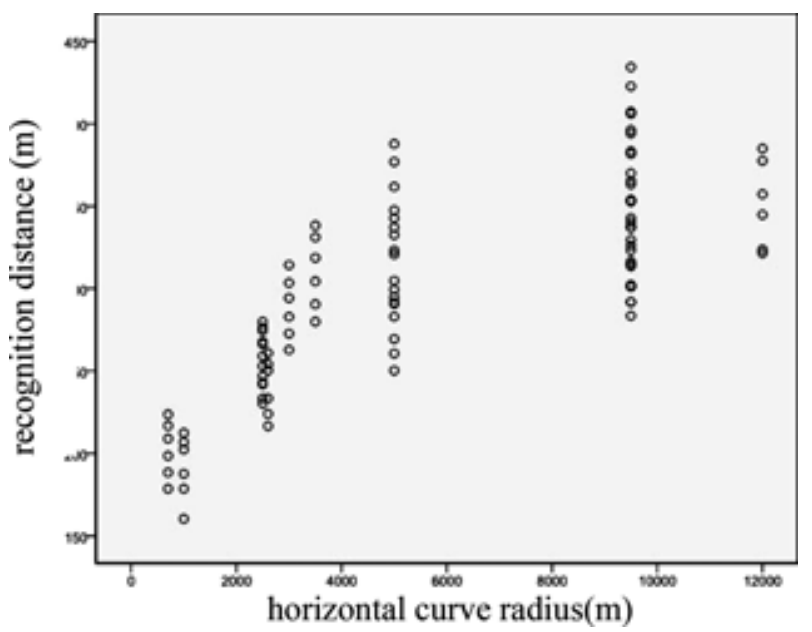

Figure 2: Distribution of recognition distance versus horizontal curve radius at night. 


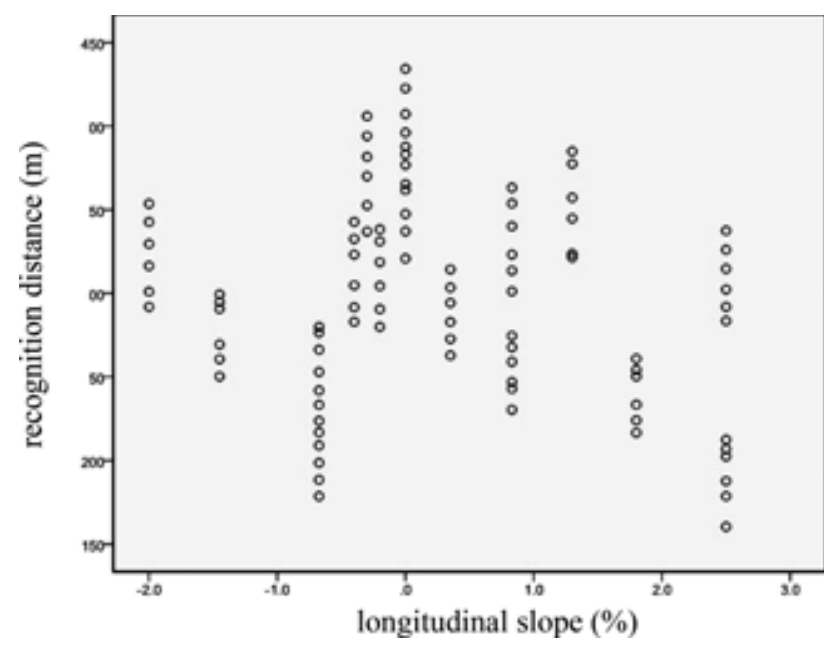

Figure 3: Distribution of recognition distance versus longitudinal slope at night.

vertical slope is zero or close to zero. It reduces in uphill segment and increases, after a dip at $0.5 \%$ slope, at downhill segment at night.

\subsection{Modeling recognition distance}

The preliminary results show the potential relationship between recognition distance and other variables. Different functional forms were explored with SPSS (Statistical Product and Service Solution) program with results listed in Table 4. SPSS is among the most widely used programs for statistical analysis.

The following model has the highest $R^{2}$ of 0.983 ; thus, it is considered to be the best model to determine the relationship.

$$
S=-1.15 v+57.8 \ln R+80.54 \mathrm{e}^{-1.72 i}-104
$$

where, $S$ is the driver's identification distance, $\mathrm{m} ; v$ is the driving speed, $\mathrm{km} / \mathrm{h} ; R$ is the horizontal curve radius, $\mathrm{m}$; and $i$ is the longitudinal slope.

\section{DRIVER SPEED PERCEPTION}

\subsection{Between daytime and nighttime}

Another interesting result from this study is the driver speed perception. During each experiment run, the on-board passenger asked the drivers to estimate their driving speed. Average driver's estimated speed data are listed in Table 5.

The results in Table 4 show that generally there is a gap between actual driving speed and drivers' estimated speed. The gap varies depending on other factors investigated in this study. During the daytime, driving speed is almost the same as estimated speed when driving speed is 70 and $80 \mathrm{~km} / \mathrm{h}$. At nighttime, drivers tend to underestimate the driving speed when driving speed is less than $90 \mathrm{~km} / \mathrm{h}$, and overestimate when the driving speed is more than $100 \mathrm{~km} / \mathrm{h}$. Drivers tend to overestimate the speed at curves with small radius both 
Table 4: Nighttime recognition distance models.

\begin{tabular}{rlcccccc}
\hline No. & \multicolumn{1}{c}{ Relation models } & $\mathrm{a}$ & $\mathrm{b}$ & $\mathrm{c}$ & $\mathrm{d}$ & $\mathrm{k}$ & $R^{2}$ \\
\hline 1 & $S=\mathrm{a} \times v+\mathrm{b} \times R+\mathrm{c} \times i+\mathrm{k}$ & -1.15 & 0.014 & -34.8 & - & 366 & 0.916 \\
2 & $S=\mathrm{a} \times v+\mathrm{b} \times R+\mathrm{c} \times \mathrm{e}^{\mathrm{d} \times i}+\mathrm{k}$ & -1.15 & 0.013 & 97.5 & -1.59 & 298 & 0.968 \\
3 & $S=\mathrm{a} \times v+\mathrm{b} \times \mathrm{e}^{\mathrm{c} \times R}+\mathrm{d} \times i+\mathrm{k}$ & -1.15 & $3.25 \mathrm{E} 5$ & 0.00 & -34.8 & $-3.24 \mathrm{E} 5$ & 0.918 \\
4 & $S=\mathrm{a} \times v+\mathrm{b} \times \ln R+\mathrm{c} \times i+\mathrm{k}$ & -1.15 & 60.3 & -27.9 & - & -68.8 & 0.942 \\
5 & $S=\mathrm{a} \times v+\mathrm{b} \times \ln R+\mathrm{c} \times \mathrm{e}^{\mathrm{d} \times i}+\mathrm{k}$ & -1.15 & 57.8 & 80.5 & -1.72 & -104 & 0.983 \\
6 & $S=\mathrm{a} \times v+\mathrm{b} \times R^{\mathrm{c}}+\mathrm{d} \times i+\mathrm{k}$ & -1.15 & 17.5 & 0.299 & -30.1 & 218 & 0.952 \\
7 & $S=\mathrm{a} \times \ln v+\mathrm{b} \times R+\mathrm{c} \times i+\mathrm{k}$ & 106 & 0.014 & -34.8 & - & 739 & 0.917 \\
8 & $S=\mathrm{a} \times \ln v+\mathrm{b} \times R+\mathrm{c} \times \mathrm{e}^{\mathrm{d} \times i}+\mathrm{k}$ & -106 & 0.013 & 97.5 & -1.59 & 671 & 0.966 \\
9 & $S=\mathrm{a} \times \ln v+\mathrm{b} \times \mathrm{e}^{\mathrm{c} \times R}+\mathrm{d} \times i+\mathrm{k}$ & -106 & $3.36 \mathrm{E} 5$ & 0.00 & -34.8 & $-3.36 \mathrm{E} 5$ & 0.917 \\
10 & $S=\mathrm{a} \times \ln v+\mathrm{b} \times \ln R+\mathrm{c} \times i+\mathrm{k}$ & -106 & 60.3 & -27.9 & - & 305 & 0.941 \\
11 & $S=\mathrm{a} \times \ln v+\mathrm{b} \times \ln R+\mathrm{c} \times \mathrm{e}^{\mathrm{d} \times i}+\mathrm{k}$ & -106 & 57.8 & 80.5 & -1.71 & 269 & 0.981 \\
12 & $S=\mathrm{a} \times \ln v+\mathrm{b} \times R^{\mathrm{c}}+\mathrm{d} \times i+\mathrm{k}$ & -106 & 17.5 & 0.299 & -30.1 & 591 & 0.951 \\
13 & $S=\mathrm{a} \times \mathrm{e}^{\mathrm{b} \times v}+\mathrm{c} \times R+\mathrm{d} \times i+\mathrm{k}$ & -143 & 0.005 & 0.014 & -34.8 & 487 & 0.919 \\
14 & $S=\mathrm{a} \times \mathrm{e}^{\mathrm{b} \times v}+\mathrm{c} \times \ln R+\mathrm{d} \times i+\mathrm{k}$ & -143 & 0.055 & 60.3 & -27.9 & 51.9 & 0.942 \\
15 & $S=\mathrm{a} \times v^{\mathrm{b}}+\mathrm{c} \times R+\mathrm{d} \times i+\mathrm{k}$ & -0.079 & 1.50 & 0.014 & -34.8 & 331 & 0.919 \\
16 & $S=\mathrm{a} \times v^{\mathrm{b}}+\mathrm{c} \times \ln R+\mathrm{d} \times i+\mathrm{k}$ & -0.079 & 1.50 & 60.3 & -27.9 & -104 & 0.942 \\
\hline
\end{tabular}

during the daytime and during the nighttime. The driver's speed estimation versus actual speed is shown in Fig. 4.

It is clear that driver estimated speeds deviated more at nighttime compared with that at daytime.

\subsection{Estimated speed at night}

The gap between driver estimated speed at night and horizontal curve radius at different driving speed is illustrated in Fig. 5, which shows that drivers' estimated speed varies differently from driving speed by horizontal curve radius.

When driving speed ranges from $70 \mathrm{~km} / \mathrm{h}$ to $90 \mathrm{~km} / \mathrm{h}$, the gaps are not noticeable. When driving speed ranges from $100 \mathrm{~km} / \mathrm{h}$ to $120 \mathrm{~km} / \mathrm{h}$, drivers' estimated speed decreases with increasing horizontal curve radius.

Drivers' estimated speed versus longitudinal slope corresponding to different driving speeds is shown in Fig. 6.

It can be found that the drivers' estimated speed varies randomly with the increasing longitudinal slope. According to the regression analysis, there is a weak relationship between the estimated speed and longitudinal slope at night.

\subsection{Modeling drivers' estimated speed}

According to the above analysis, various models were developed to best capture the relationship between drivers' estimated speed and actual driving speed and horizontal curve radius. All models explored are given in Table 6 . 
Table 5: Diver estimated speed under different speed and highway alignment.

\begin{tabular}{|c|c|c|c|c|c|c|c|c|c|c|c|c|}
\hline Driving speed & & & At & daytir & & & & & & night & & \\
\hline Alignment & 70 & 80 & 90 & 100 & 110 & 120 & 70 & 80 & 90 & 100 & 110 & 120 \\
\hline Curve with little radius & 70 & 80 & 100 & 110 & 120 & 130 & 70 & 70 & 95 & 110 & 130 & 140 \\
\hline $\begin{array}{l}\text { Curve slope with } \\
\text { medium radius }\end{array}$ & 70 & 80 & 90 & 95 & 115 & 125 & 60 & 80 & 90 & 110 & 130 & 130 \\
\hline $\begin{array}{l}\text { Curve with medium } \\
\text { radius }\end{array}$ & 70 & 80 & 90 & 100 & 110 & 120 & 60 & 75 & 90 & 100 & 125 & 130 \\
\hline $\begin{array}{l}\text { Curve slope with large } \\
\text { radius }\end{array}$ & 70 & 80 & 92 & 100 & 110 & 120 & 60 & 75 & 85 & 105 & 120 & 125 \\
\hline Curve with large radius & 70 & 78 & 90 & 100 & 110 & 115 & 60 & 70 & 85 & 100 & 120 & 120 \\
\hline Straight and slope section & 70 & 80 & 90 & 100 & 105 & 110 & 60 & 70 & 80 & 105 & 110 & 120 \\
\hline $\begin{array}{l}\text { Flat and straight } \\
\text { section }\end{array}$ & 70 & 80 & 90 & 100 & 100 & 110 & 60 & 70 & 80 & 100 & 110 & 120 \\
\hline
\end{tabular}

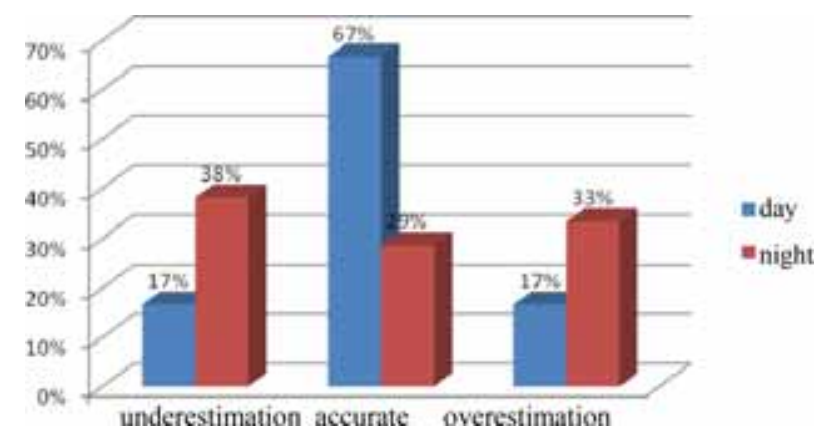

Figure 4: Accuracy of driver speed perception.

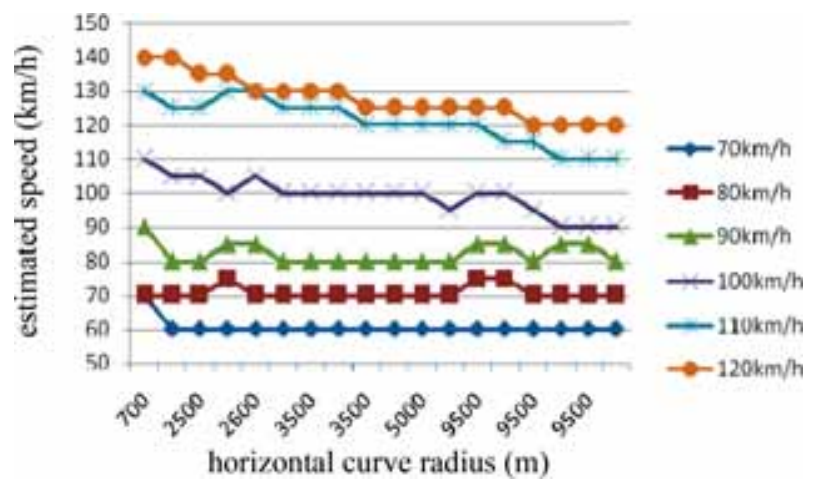

Figure 5: Driver estimated speed versus horizontal curve radius. 


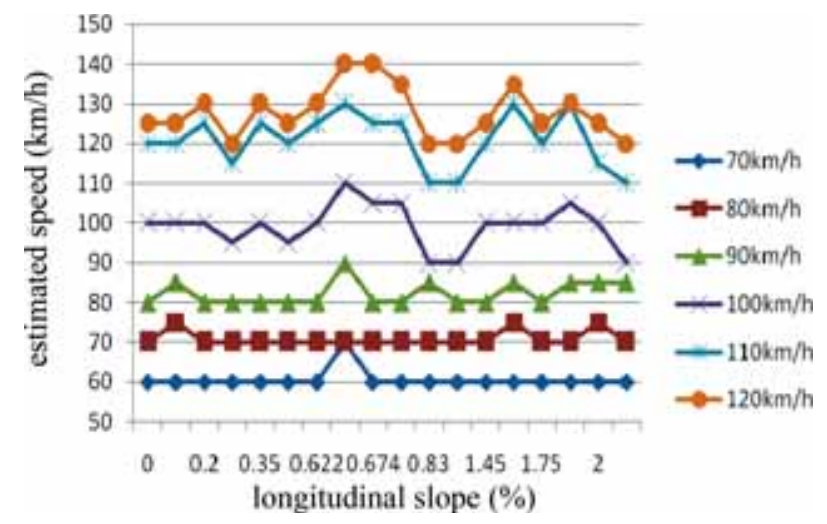

Figure 6: Driver estimated speed versus longitudinal slope.

Table 6: Driver estimated speed models at night.

\begin{tabular}{llccccc}
\hline & Relation models & $\mathrm{a}$ & $\mathrm{b}$ & $\mathrm{c}$ & $\mathrm{k}$ & $R^{2}$ \\
\hline 1 & $v_{\mathrm{p}}=\mathrm{a} \times v+\mathrm{b} \times R+\mathrm{k}$ & 1.47 & -0.001 & - & 38.5 & 0.959 \\
2 & $v_{\mathrm{p}}=\mathrm{a} \times v+\mathrm{b} \times \ln R+\mathrm{k}$ & 1.44 & -4.20 & - & -7.77 & 0.962 \\
3 & $v_{\mathrm{p}}=\mathrm{a} \times v+\mathrm{b} \times \mathrm{e}^{\mathrm{c} \times \mathrm{R}}+\mathrm{k}$ & 1.44 & -11437 & 0.000 & 11398 & 0.960 \\
4 & $v_{\mathrm{p}}=\mathrm{a} \times \ln v+\mathrm{b} \times R+\mathrm{k}$ & 133 & -0.001 & - & -503 & 0.946 \\
5 & $v_{\mathrm{p}}=\mathrm{a} \times \ln v+\mathrm{b} \times \ln R+\mathrm{k}$ & 133 & -4.20 & - & -473 & 0.949 \\
6 & $v_{\mathrm{p}}=\mathrm{a} \times \ln v+\mathrm{b} \times \mathrm{e}^{\mathrm{c} \times \mathrm{R}}+\mathrm{k}$ & 133 & -10326 & 0.000 & 9823 & 0.946 \\
7 & $v_{\mathrm{p}}=\mathrm{a} \times \mathrm{e}^{\mathrm{b} \times \mathrm{v}}+\mathrm{c} \times R+k$ & 159 & 0.005 & -0.001 & -169 & 0.960 \\
8 & $v_{\mathrm{p}}=\mathrm{a} \times \mathrm{e}^{\mathrm{b} \times \mathrm{v}}+\mathrm{c} \times \ln R+k$ & 159 & 0.005 & -4.20 & -138 & 0.959 \\
\hline
\end{tabular}

The best model with a highest $R^{2}$ of 0.962 algorithms is given below:

$$
v_{\mathrm{p}}=1.44 v-4.2 \ln R-7.77
$$

where, $v_{\mathrm{p}}$ is the driver estimated speed at night, $\mathrm{km} / \mathrm{h}$.

\section{MAXIMUM SPEED LIMIT AT NIGHT}

For safety, driver recognition distance needs to satisfy eqn (4).

$$
\mathrm{S} \geq \mathrm{ST}
$$

where, $S_{\mathrm{T}}$ is the stopping sight distance and is composed of three parts which are shown in eqn (5).

$$
S_{T}=S_{1}+S_{2}+S_{0}=\frac{v}{3.6} t+\frac{v^{2}}{254(\varphi+i)}+S_{0}
$$

where, $S_{1}$ is the driving distance during driver's reaction time, $\mathrm{m} ; S_{2}$ is braking distance, $\mathrm{m}$; $S_{0}$ is safe distance, $\mathrm{m} ; t$ is driver's reaction time, $\mathrm{s} ; \varphi$ is pavement's friction coefficient. 
Combining eqns (2), (4), and (5), we get:

$$
\frac{v^{2}}{254(\varphi+i)}+1.844 v+109-57.8 \ln R-80.54 e^{-1.72 i} \leq 0
$$

Thus, the theoretical maximum speed limit on freeway at night can be obtained below:

$$
v_{\mathrm{lt}}=\left(\sqrt{0.85-\frac{109-57.8 \ln R-80.54 e^{-1.72 i}}{254(\varphi+i)}}-0.922\right) \times 254 \times(\varphi+i)
$$

where, $v_{\mathrm{lt}}$ is the theoretical maximum speed limit value on freeway at night, $\mathrm{km} / \mathrm{h}$. $\varphi$ in eqn (6) can be taken as 0.3 , with the pavement being wet and speed being $120 \mathrm{~km} / \mathrm{h}$. Moreover, considering the load of all the driving wheels of the car accounting for $50 \%$ to $65 \%$ of total weight, $\varphi$ can be multiplied by 0.5 according to the most adverse condition.

According to above analysis, affected by highway alignment and speed, driver speed perception will produce deviation. Therefore, it is necessary to correct theoretical maximum speed limit on freeway at night. According to eqn (3), driver estimated speed deviation can be calculated by eqn (8).

$$
\Delta v=v_{\mathrm{lt}}-\frac{1}{1.44}\left(v_{\mathrm{lt}}+4.2 \ln R+7.77\right)
$$

where, $\Delta v$ is the correction value of theoretical maximum speed limit value on freeway at night, $\mathrm{km}$.

Thus, the corrected theoretical maximum speed limit value on freeway at night can be expressed by:

$$
v_{\mathrm{lc}}=v_{\mathrm{lt}}+\Delta v
$$

where, $v_{\mathrm{lc}}$ is the corrected theoretical maximum speed limit value on freeway at night, $\mathrm{km} / \mathrm{h}$.

Taking new-constructed section of Chang-Song freeway as example, the maximum speed limit on freeway at night was calculated as listed in Table 7.

\section{CONCLUSIONS}

The results can be summarized below:

1. Driver recognition distance at daytime is more than that at night, and it decreases with an increase in the driving speed and longitudinal slope; and increases with an increase in the horizontal curve radius. The modeling results show that there is a negative linear, positive logarithm, negative exponent relationship between the driver recognition distance at night and driving speed, horizontal curve radius, and longitudinal slope, respectively.

2. Driver speed perception is less accurate at night, and at daytime, it is accurate at low speed and deviated at high speed. At night, drivers tend to underestimate speed at low speed and overestimate speed at high speed. There is no relationship between driver estimated speed and longitudinal slope at night. Established model shows that there is a positive linear, negative logarithm relationship between driver estimated speed at night and driving speed and horizontal curve radius, respectively.

3. Based on driver recognition distance and stopping sight distance, a method to calculate was given to obtain maximum speed limit value on freeway at night. 


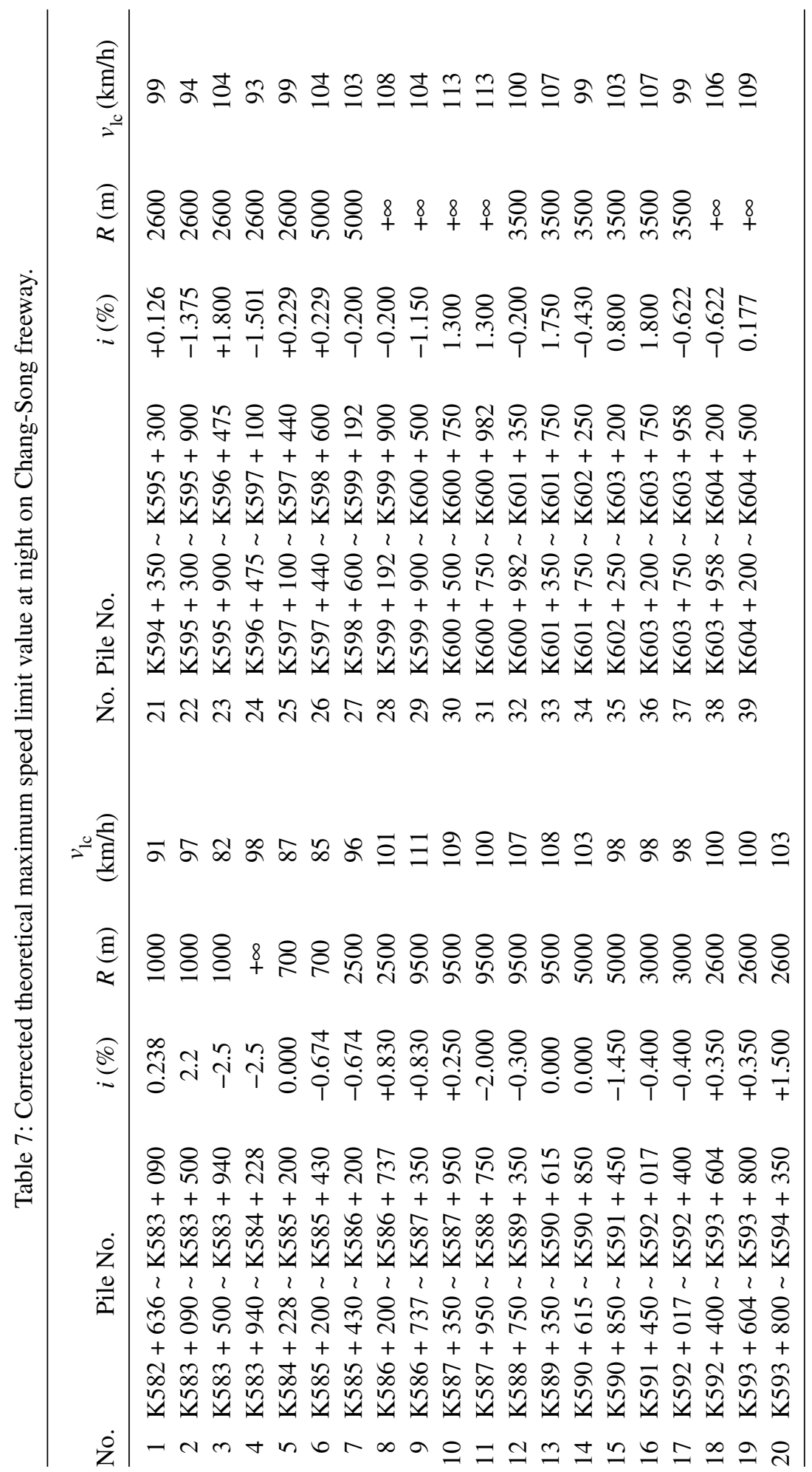


It is worth emphasizing that this paper is an initial research and requires further study to achieve a higher degree of efficiency. Implications of results need further investigation.

\section{REFERENCES}

[1] Konstantopoulos, P., Chapman, P. \& Crundall, D., Driver's visual attention as a function of driving experience and visibility: using a driving simulator to explore drivers' eye movements in day, night and rain driving. Accident Analysis and Prevention, 42(3), pp. 827-834, 2010. doi: http://dx.doi.org/10.1016/j.aap.2009.09.022

[2] Easa, S.M., Reed, M.J., Russo, F., Dabbour, E., Mehmood, A. \& Curtis, K., Effect of increasing road light luminance on night driving performance of older adults. International Journal of Engineering and Applied Sciences, 6(1), pp. 41-48, 2010.

[3] Babizhayev, M.A., Minasyan, H. \& Richer, S.P., Cataract halos: a driving hazard in aging populations. Implication of the Halometer DG test for assessment of intraocular light scatter. Applied Ergonomics, 40(3), pp. 545-553, 2009. doi: http://dx.doi. org/10.1016/j.apergo.2007.09.003

[4] Hua, W. \& Donnell, E.T., Models of acceleration and deceleration rates on a complex two-lane rural highway: results from a night driving experiment. Transportation Research Part F, 13(6), pp. 397-408, 2010. doi: http://dx.doi.org/10.1016/j. trf.2010.06.005

[5] Horberry, T., Anderson, J. \& Regan, M.A., The possible safety benefits of enhanced road markings: a driving simulator evaluation. Transportation Research Part $F, \mathbf{9}(\mathbf{1})$, pp. 77-87, 2006. doi: http://dx.doi.org/10.1016/j.trf.2005.09.002

[6] Baker, R.G.V., On the quantum mechanics of optic flow and its application to driving in uncertain environments. Transportation Research Part F, 2(1), pp. 27-53, 1999. doi: http://dx.doi.org/10.1016/S1369-8478(99)00005-4

[7] Campbell, J.L., Richard, C.M. \& Brown, J.L., Chapter 17: speed perception, speed choice, and speed control. NCHRP Report 600C: Human Factors Guidelines for Road Systems, Transportation Research Board, Washington, D.C, 2010.

[8] Suh, W., Park, P.Y.J., Park, C.H. \& Chon, K.S., Relationship between speed, lateral placement, and drivers' eye movement at two-lane rural highways. Journal of Transportation Engineering, 132(8), pp. 649-653, 2006. doi: http://dx.doi.org/10.1061/ (ASCE)0733-947X(2006)132:8(649)

[9] Henriette, W.W., Türker, Ö. \& Timo, L., Cross-cultural differences in drivers' speed choice. Accident Analysis and Prevention, 41(4), pp. 816-819, 2009. doi: http://dx.doi. org/10.1016/j.aap.2009.04.004

[10] Pasetto, M. \& Manganaro, A., Night speed negotiation on rural road s-shaped curves: discussion of an experimental case-study. Proceedings of the Fifth International Driving Symposium on Human Factors in Driver Assessment, Training and Vehicle Design, pp. 475-481, 2009.

[11] Mannering, F., An empirical analysis of driver perceptions of the relationship between speed limits and safety. Transportation Research Part F, 12(2), pp. 99-106, 2009. doi: http://dx.doi.org/10.1016/j.trf.2008.08.004 